\title{
Evaluation of the Overall Accuracy of the DeLaval Cell Counter for Somatic Cell Counts in Ovine Milk
}

\author{
C. Gonzalo, ${ }^{1}$ B. Linage, J. A. Carriedo, F. de la Fuente, and F. San Primitivo \\ Departamento de Producción Animal, Facultad de Veterinaria, Universidad de León, 24071-León, Spain
}

\begin{abstract}
The DeLaval cell counter (DCC) is a portable device designed for on-farm somatic cell count (SCC) analysis in bovine milk. This study evaluated the performance of the DCC when analyzing ovine milk. A total of 29 composite ovine milk samples, ranging between $20 \times 10^{3}$ and $2,200 \times 10^{3}$ cells $/ \mathrm{mL}$, were divided into 15 aliquots/ milk sample corresponding to 5 SCC methods using 3 types of preservation (unpreserved, azidiol, and bronopol). The SCC methods were the Fossomatic (FSCC), the DCC in undiluted samples, and the DCC in samples diluted 1:1 in 3 different types of diluents (PBS + Triton X-100, PBS + ethidium bromide + Triton X-100, and PBS + propidium iodide + Triton X-100). All analyses were carried out in duplicate. In addition, each sample was analyzed in quadruplicate by the direct microscopic method (DMSCC) using Pyronin Y-methyl green as a stain. Comparison of methods was based on overall accuracy studies (means comparison, repeatability, and regression studies vs. DMSCC and FSCC as reference methods). The DCC methods used to analyze milk samples diluted in staining solution (with ethidium bromide or propidium iodide) showed large coefficients of regression $(b=0.91$ to 1.01$)$ and correlation $(r>0.99)$ when compared with the DMSCC and FSCC methods. In these samples the DCC gave repeatability values $\left(\mathrm{s}_{\mathrm{r}}=33\right.$ to $48 \times 10^{3}$ cells $\left./ \mathrm{mL}\right)$ similar to the DMSCC $\left(\mathrm{s}_{\mathrm{r}}=36 \times 10^{3}\right.$ cells $/ \mathrm{mL}$ ), and their log SCC means (5.52 to 5.54) did not differ from the reference value (5.54). However, undiluted samples analyzed by the DCC method showed large standard deviations of repeatability and SCC values lower than those by the DMSCC or FSCC methods, probably because of the high solids content in ovine milk. The type of preservation did not affect the outcomes. Consequently, the DCC was determined to be accurate when analyzing diluted ovine milk based on comparison with the SCC reference methods.
\end{abstract}

Key words: sheep milk, somatic cell count, DeLaval cell counter, accuracy

Received May 30, 2006.

Accepted July 26, 2006

${ }^{1}$ Corresponding author: dp2cga@unileon.es

\section{INTRODUCTION}

Ovine milk is very important in Mediterranean countries, and some of these countries have well-established milk recording schemes for the SCC of milk (Gonzalo et al., 1994; El-Saied et al., 1998). The accuracy of milk SCC is very important to veterinarians, producers, and the dairy industry, because the SCC is a useful predictor of IMI in dairy ewes (Marco, 1994; González-Rodríguez et al., 1995; Gonzalo et al., 2002). Moreover, standardization of SCC counters for small ruminant milk is essential in SCC laboratories and equipment to guarantee accuracy and reproducibility of the results. For ovine milk, after staining the DNA of the nuclei with a fluorescent stain (i.e., ethidium bromide; EB), the fluoro-optoelectronic SCC counters, which are based on disk or flow cytometry, showed suitable overall accuracy when compared with the reference method (Gonzalo et al., 2004). Further, flow cytometry was slightly more precise and repeatable than disk cytometry, particularly for high SCC. In addition, recent studies on SCC variation have shown that preservation, analytical temperature, and storage type can have a significant influence on the SCC in ovine and caprine milk (Gonzalo et al., 2003; Martínez et al., 2003; Sánchez et al., 2005).

However, the Fossomatic (FSCC; Foss Electric, Hillerød, Denmark) method requires cumbersome and expensive equipment, so less expensive alternative methods and portable devices for on-farm use would be of great interest in mastitis control strategies. The DeLaval cell counter (DCC; DeLaval International AB, Tumba, Sweden) is a portable, battery-operated optical cell counter that gives the measuring results in less than 1 min (about $40 \mathrm{~s} / \mathrm{sample}$ ). A cassette, which contains small amounts of propidium iodide (PI) as the fluorescent stain, is used to collect milk before cell counting. A piston carries the sample toward a counting window that is exposed to an LED light source. Cell nuclei give fluorescent signals recorded in an image that is used to determine the SCC in milk. The DCC has been successfully designed for SCC determination in raw bovine milk (DeLaval, 2005). However, no information is available about performance of the DCC in ovine milk, which contains a greater content of total solids than bovine milk. 
There is evidence that some SCC methods and devices show significant bias in ovine milk (IDF, 2006).

The international IDF standard 128A (IDF, 1999) defines and evaluates the overall accuracy of indirect methods of milk analysis when compared with the reference methods. Based on this standard, an attempt should be made to evaluate the accuracy of the DCC method for SCC in ovine milk. Knowledge of regression deviations and mean bias among SCC methods and among analytical conditions within methods in ovine milk is essential for carrying out intra- and interlaboratory quality control tests, with the aim of guaranteeing reproducibility and accuracy of the results.

The objective of this study was to determine the overall accuracy of the DCC in ovine milk, contrasting it with the direct microscopy (DMSCC) and FSCC methods, in diluted and undiluted milk samples under different staining solution and preservation conditions.

\section{MATERIALS AND METHODS}

From Assaf and Churra ewes in different stages of lactation, a total of 29 composite ovine milk samples ranging between $20 \times 10^{3}$ and $2,200 \times 10^{3}$ cells $/ \mathrm{mL}$ were divided into 15 aliquots that, in turn, were divided into 3 groups according to the preservation type: 5 unpreserved aliquots (UP), 5 aliquots with $0.3 \%$ azidiol (AZ), and 5 aliquots with $0.2 \%$ bronopol (BR). Azidiol composition was $0.75 \mathrm{~g}$ of cloramphenicol, $18 \mathrm{~g}$ of sodium azide, 10 $\mathrm{mL}$ of ethanol, $45 \mathrm{~g}$ of trisodium citrate 5.5-hydrate, 0.35 $\mathrm{g}$ of bromophenol blue, and deionized water up to $1 \mathrm{~L}$. The first 2 aliquots in each preservation type were not diluted and were analyzed by the DCC and Fossomatic 5000 (Foss Electric), respectively, whereas the other 3 aliquots were diluted 1:1 in different diluents and analyzed by the DCC. These diluents were as follows: PBS + Triton X-100 $(0.2 \%)$, PBS + EB $(0.025 \mathrm{mg} / \mathrm{mL})+$ Triton $\mathrm{X}-100(0.2 \%)$, and PBS + PI $(0.025 \mathrm{mg} / \mathrm{mL})+$ Triton X$100(0.2 \%)$, for the third, fourth, and fifth aliquot, respectively. The DCC analyses were made at ambient temperature $\left(22^{\circ} \mathrm{C}\right)$ within $4 \mathrm{~h}$ postcollection. Milk was heated to $40^{\circ} \mathrm{C}$ before the FSCC determination, and the FSCC was carried out within $24 \mathrm{~h}$ postcollection. All analyzes were carried out in duplicate. Before and during the experiment, accuracy and linearity of the FSCC were calibrated by using bovine milk standards of known SCC (between 0 and $2,000 \times 10^{3}$ cells $/ \mathrm{mL}$ ) provided by Cecalait (Poligny, France) so that the milk samples analyzed were within the range covered by the DCC evaluation.

In addition, the SCC of each original milk sample was determined in quadruplicate by the DMSCC method, according to IDF Regulation 148A (IDF, 1995) adapted to ovine milk by Gonzalo et al. (2003, 2004). Slides were previously treated with poly-L-lysine to increase the ad- herence of the film of milk. The method used to stain the film was pyronin Y-methyl green. The working factor was 2,200 in all cases. The fat, protein, and solids content also were determined in duplicate in all samples by a MilkoScan FT 6000 (Foss Electric). This design enabled us to determine the overall accuracy of the analytical conditions most frequently used in milk analysis. A total of 986 analytical determinations of SCC were carried out, 696 by the DCC, 174 by the FSCC, and 116 by the DMSCC.

\section{Statistical Analyses}

The DMSCC method and 15 analytical conditions were compared. These 15 conditions corresponded to 5 methods (FSCC, DCC in undiluted samples, and DCC in samples diluted in 3 different types of diluents), and 3 preservation types (UP, $\mathrm{AZ}$, and $\mathrm{BR}$ ). Representation of all 16 analytical conditions were DMSCC for the reference method; FSCC-UP, FSCC-AZ, and FSCC-BR for the Fossomatic method; DCC-UP, DCC-AZ, and DCC-BR for the DCC in undiluted samples, and DCC(PBS)-UP, DCC(PBS)-AZ, DCC(PBS)-BR, DCC(PBS + PI)-UP, $\mathrm{DCC}(\mathrm{PBS}+\mathrm{PI})-\mathrm{AZ}, \mathrm{DCC}(\mathrm{PBS}+\mathrm{PI})-\mathrm{BR}, \mathrm{DCC}(\mathrm{PBS}+$ $\mathrm{EB})-\mathrm{UP}, \mathrm{DCC}(\mathrm{PBS}+\mathrm{EB})-\mathrm{AZ}$, and DCC(PBS + EB)-BR for the DCC in diluted (1:1) samples.

These analytical conditions were compared according to 3 types of statistical studies: comparison of means, standard deviations of repeatability, and regression. The comparison of means was carried out by using the GLM (procedure GLM; SAS Inst. Inc., Cary NC). The statistical model used was

$$
\mathrm{Y}_{\mathrm{ijk}}=\mu+\mathrm{A}_{\mathrm{i}}+\mathrm{E}_{\mathrm{j}}+\mathrm{e}_{\mathrm{ijk}},
$$

where $Y_{\mathrm{ijk}}$ is the dependent variable $\log \mathrm{SCC}, \mu$ is the mean, $A_{i}$ is the effect of 16 previously defined analytical conditions, $E_{j}$ is the effect of ewe $(n=29)$, and $e_{i j k}$ is the residual effect, in which 2 replicates were considered because analytical determinations were performed in duplicate.

The standard deviation of repeatability $\left(\mathrm{s}_{\mathrm{r}}\right.$ and its relative value, $s_{r} \times 100 / \bar{x}$, where $\bar{x}$ is the arithmetic mean of the SCC) for each analytical condition was calculated according to international IDF Standard 128A (IDF, 1999) using the formula

$$
\mathrm{S}_{\mathrm{r}}=\left(\frac{1}{2 \mathrm{q}} \sum_{i=1}^{q} \mathrm{w}_{\mathrm{i}}^{2}\right)^{1 / 2}
$$

where $q$ is the number of samples and $\mathrm{w}_{\mathrm{i}}$ is the absolute difference between duplicate results of SCC methods. In the case of the DMSCC, where the SCC was determined 
in quadruplicate, the standard deviation of each of the 6 possible duplicates was calculated and averaged.

A linear regression was performed to establish the relationship between the DMSCC and FSCC (used as the reference methods), and each analytical condition. Because the SCC analytical conditions were carried out in duplicate for the DCC and FSCC, and in quadruplicate for the DMSCC, the arithmetic mean of the 2 or 4 replicates was determined beforehand. Estimates were carried out from 29 observations (pairs of data) for each regression line. The corresponding intercept (a), coefficient of regression (b), and coefficient of determination $\left(\mathrm{R}^{2}\right)$ were estimated in all cases by using a regression (procedure REG; SAS Inst. Inc., Cary, NC). Forced by $a=0$, linear regressions were also performed to estimate the $b$ values of regressions.

Finally, a statistical analysis was carried out according to GLM (procedure GLM; SAS Inst. Inc., Cary, NC) using the mathematical model

$$
\mathrm{Y}_{\mathrm{ijkl}}=\mu+\mathrm{E}_{\mathrm{i}}+\mathrm{M}_{\mathrm{j}}+\mathrm{P}_{\mathrm{k}}+\mathrm{MP}_{\mathrm{jk}}+\mathrm{e}_{\mathrm{ijk} \mathrm{l}},
$$

where $Y_{i j k l}$ is the $\log$ SCC; $E_{i}$ is the ewe effect $(n=29)$; $\mathrm{P}_{\mathrm{k}}$ is the preservation type effect, and $\mathrm{M}_{\mathrm{j}}$ is the SCC method (5 types). The methods considered were FSCC, DCC in undiluted samples, and DCC in diluted (1:1) samples in the 3 diluents previously mentioned. The analytical determinations were carried out in duplicate.

\section{RESULTS AND DISCUSSION}

Table 1 shows the comparison of SCC mean values obtained for the analytical conditions and methods assayed in ovine milk. The SCC values obtained by FSCC analytical conditions (log SCC: 5.54 to 5.55; geometric means: 348 to $355 \times 10^{3}$ cell $/ \mathrm{mL}$ ) and the DMSCC method ( 5.54 and $344 \times 10^{3}$ cells $/ \mathrm{mL}$ ) did not differ between methodologies. Within the DCC method, undiluted samples analyzed by the DCC gave lesser $(P<$ 0.05 ) SCC values (5.33 to 5.36, and 215 to $229 \times 10^{3}$ cells $/ \mathrm{mL}$ ) than those analyzed by the DMSCC and FSCC methods. The corrected (multiplied by 2) SCC from diluted (1:1) milk (5.49 to 5.54 , and 307 to $343 \times 10^{3} / \mathrm{mL}$ ) were closer to reference values than SCC from undiluted samples, particularly when PBS was added with EB (5.52 to 5.53 , and 326 to $336 \times 10^{3} / \mathrm{mL}$ ) or PI (5.53 to 5.54 , and 335 to $343 \times 10^{3} / \mathrm{mL}$ ). These SCC values obtained from diluted (1:1) samples in staining solution and analyzed by the DCC method were similar to those obtained by the DMSCC (Table 1). In ovine milk, significant variations in SCC usually were obtained among methods and analytical conditions, and also among instruments within the same method. For example, variations of SCC geometric means up to $20 \%$ have been
Table 1. Least squares means of log SCC, geometric means of the SCC, and standard deviations of repeatability $\left(\mathrm{s}_{\mathrm{r}}\right.$ and $\mathrm{s}_{\mathrm{r}} \%$ ) for each of the 16 analytical conditions analyzed by direct microscopy (DMSCC), the Fossomatic (FSCC), and the DeLaval cell counter (DCC)

\begin{tabular}{|c|c|c|c|c|}
\hline $\begin{array}{l}\text { Analytical } \\
\text { condition }^{1}\end{array}$ & $\begin{array}{l}\text { Least } \\
\text { squares } \\
\text { means, }{ }^{2} \\
(\log \mathrm{SCC})\end{array}$ & $\begin{array}{l}\mathrm{SCC} \\
\left(\times 10^{3} / \mathrm{mL}\right) \\
\text { geometric } \\
\text { means }\end{array}$ & $\mathrm{s}_{\mathrm{r}}$ & $\mathrm{s}_{\mathrm{r}} \%$ \\
\hline FSCC-BR & $5.550^{\mathrm{a}}$ & 355 & 15 & 2.49 \\
\hline FSCC-AZ & $5.544^{\mathrm{ab}}$ & 350 & 13 & 2.21 \\
\hline FSCC-UP & $5.542^{\mathrm{ab}}$ & 348 & 16 & 2.74 \\
\hline DMSCC & $5.536^{\mathrm{abc}}$ & 344 & $36^{3}$ & 6.05 \\
\hline $\mathrm{DCC}(\mathrm{PBS}+\mathrm{PI})-\mathrm{BR}$ & $5.536^{\text {abcd }}$ & 343 & 33 & 6.07 \\
\hline $\mathrm{DCC}(\mathrm{PBS}+\mathrm{PI})-\mathrm{AZ}$ & $5.531^{\text {abcd }}$ & 340 & 41 & 7.55 \\
\hline $\mathrm{DCC}(\mathrm{PBS}+\mathrm{EB})-\mathrm{UP}$ & $5.526^{\text {abcd }}$ & 336 & 36 & 6.49 \\
\hline $\mathrm{DCC}(\mathrm{PBS}+\mathrm{PI})-\mathrm{UP}$ & $5.525^{\mathrm{bcd}}$ & 335 & 36 & 6.61 \\
\hline $\mathrm{DCC}(\mathrm{PBS}+\mathrm{EB})-\mathrm{AZ}$ & $5.516^{\text {cde }}$ & 328 & 48 & 8.75 \\
\hline $\mathrm{DCC}(\mathrm{PBS}+\mathrm{EB})-\mathrm{BR}$ & $5.514^{\text {de }}$ & 326 & 42 & 7.76 \\
\hline $\mathrm{DCC}(\mathrm{PBS})-\mathrm{BR}$ & $5.496^{\text {ef }}$ & 314 & 35 & 6.90 \\
\hline DCC(PBS)-UP & $5.493^{\text {ef }}$ & 311 & 41 & 8.18 \\
\hline DCC(PBS)-AZ & $5.487^{\mathrm{f}}$ & 307 & 34 & 6.88 \\
\hline DCC-UP & $5.359^{\mathrm{g}}$ & 229 & 46 & 12.63 \\
\hline DCC-AZ & $5.358^{\mathrm{g}}$ & 228 & 57 & 15.87 \\
\hline DCC-BR & $5.332^{\mathrm{h}}$ & 215 & 69 & 19.60 \\
\hline
\end{tabular}

${ }^{\mathrm{a}-\mathrm{h}}$ Means within a column not sharing a common superscript letter differ $(P<0.05)$.

${ }^{1} \mathrm{FSCC}-\mathrm{BR}=$ Aliquots preserved with bronopol (BR) and analyzed by the FSCC (Foss Electric, Hillerød, Denmark); FSCC-AZ = aliquots preserved with azidiol (AZ) and analyzed by the FSCC; FSCC-UP = aliquots unpreserved (UP) and analyzed by the FSCC; DCC(PBS + $\mathrm{PI}$-BR = aliquots BR-preserved, diluted 1:1 in PBS + propidium iodide (PI) staining solution, and analyzed by the DCC (DeLaval International AB, Tumba, Sweden); DCC(PBS + PI)-AZ = aliquots AZ-preserved, diluted 1:1 in PBS + PI staining solution, and analyzed by the DCC; DCC(PBS + EB)-UP = aliquots UP, diluted 1:1 in PBS + ethidium bromide (EB) staining solution, and analyzed by the DCC; DCC(PBS + PI)-UP = aliquots UP, 1:1 diluted in PBS + PI staining solution, and analyzed by the DCC; DCC (PBS + EB)-AZ = aliquots AZ-preserved, diluted 1:1 in PBS + EB staining solution, and analyzed by the DCC; DCC(PBS + EB)-BR = aliquots BR-preserved, diluted 1:1 in PBS + EB staining solution, and analyzed by the DCC; DCC(PBS)-BR = aliquots BR-preserved, diluted 1:1 in PBS solution, and analyzed by the DCC; DCC(PBS)-UP = aliquots UP, diluted 1:1 in PBS solution, and analyzed by the DCC; DCC(PBS)-AZ = aliquots AZ-preserved, diluted 1:1 in PBS solution, and analyzed by the DCC; DCC-UP = aliquots UP and analyzed by the DCC; DCC-AZ = aliquots AZ-preserved and analyzed by the DCC; DCC-BR = aliquots BRpreserved and analyzed by the DCC.

${ }^{2} \mathrm{SE}$ of least squares means $=0.008$ for the DCC and 0.006 for the DMSCC.

${ }^{3}$ Mean of standard deviations of all 6 possible combinations of duplicates.

described among different devices and analytical conditions for the FSCC method (Gonzalo et al., 2003, 2004). In the present study, within the DCC method, the greatest SCC differences were $<10.5 \%$ for diluted samples and $>30 \%$ for undiluted samples; consequently, the dilution decreased SCC variability and increased $(P<0.001)$ SCC accuracy.

Regarding repeated SCC, standard deviations of repeatability (Table 1) for the DMSCC (6.05\%) and FSCC (2.21 to $2.74 \%$ ) methods were similar to those found 
Table 2. Coefficients of regression (b), intercept (a), standard errors (SE), and $R^{2}$ values based on single and forced by $\mathrm{a}=0$ regression analyses between direct microscopic (as the reference method) and SCC methods and analytical conditions studied

\begin{tabular}{|c|c|c|c|c|c|c|c|}
\hline \multirow{3}{*}{$\begin{array}{l}\text { SCC methods } \\
\text { and analytical } \\
\text { conditions }^{1}\end{array}$} & \multicolumn{7}{|c|}{ Regression with the direct microscopy method } \\
\hline & \multicolumn{5}{|c|}{$y=b x+a$} & \multicolumn{2}{|c|}{$\begin{array}{c}y=b x \\
(\text { forced by } a=0)\end{array}$} \\
\hline & $\mathrm{b}$ & $\mathrm{SE}$ & $\mathrm{a}$ & SE & $\mathrm{R}^{2}$ & $\mathrm{~b}$ & $\mathrm{R}^{2}$ \\
\hline FSCC-UP & 0.964 & 0.011 & 0.20 & 0.062 & 0.996 & 1.001 & 0.995 \\
\hline FSCC-AZ & 0.971 & 0.009 & 0.16 & 0.049 & 0.998 & 1.001 & 0.997 \\
\hline FSCC-BR & 0.973 & 0.011 & 0.16 & 0.059 & 0.997 & 1.002 & 0.996 \\
\hline DCC-UP & 0.905 & 0.026 & 0.35 & 0.143 & 0.978 & 0.967 & 0.974 \\
\hline DCC-AZ & 0.850 & 0.036 & 0.65 & 0.203 & 0.953 & 0.967 & 0.934 \\
\hline DCC-BR & 0.867 & 0.042 & 0.53 & 0.236 & 0.939 & 0.963 & 0.927 \\
\hline DCC(PBS)-UP & 0.918 & 0.015 & 0.41 & 0.086 & 0.992 & 0.992 & 0.986 \\
\hline $\mathrm{DCC}(\mathrm{PBS}+\mathrm{EB})-\mathrm{UP}$ & 0.949 & 0.013 & 0.27 & 0.071 & 0.995 & 0.998 & 0.992 \\
\hline $\mathrm{DCC}(\mathrm{PBS}+\mathrm{PI})-\mathrm{UP}$ & 0.942 & 0.012 & 0.31 & 0.068 & 0.995 & 0.998 & 0.992 \\
\hline DCC(PBS)-AZ & 0.904 & 0.016 & 0.48 & 0.089 & 0.992 & 0.991 & 0.983 \\
\hline $\mathrm{DCC}(\mathrm{PBS}+\mathrm{EB})-\mathrm{AZ}$ & 0.975 & 0.023 & 0.12 & 0.129 & 0.985 & 0.997 & 0.984 \\
\hline $\mathrm{DCC}(\mathrm{PBS}+\mathrm{PI})-\mathrm{AZ}$ & 0.905 & 0.016 & 0.52 & 0.090 & 0.991 & 0.998 & 0.981 \\
\hline DCC(PBS)-BR & 0.911 & 0.019 & 0.45 & 0.106 & 0.988 & 0.993 & 0.980 \\
\hline $\mathrm{DCC}(\mathrm{PBS}+\mathrm{EB})-\mathrm{BR}$ & 0.960 & 0.016 & 0.20 & 0.088 & 0.993 & 0.996 & 0.991 \\
\hline $\mathrm{DCC}(\mathrm{PBS}+\mathrm{PI})-\mathrm{BR}$ & 0.912 & 0.013 & 0.48 & 0.073 & 0.995 & 0.999 & 0.985 \\
\hline
\end{tabular}

${ }^{1}$ FSCC-UP = Aliquots unpreserved (UP) and analyzed by the Fossomatic (FSCC; Foss Electric, Hillerød, Denmark); FSCC-AZ = aliquots preserved with azidiol (AZ) and analyzed by the FSCC; FSCC-BR = aliquots preserved with bronopol (BR) and analyzed by the FSCC; DCC-UP: aliquots UP and analyzed by the DeLaval cell counter (DCC; DeLaval International AB, Tumba, Sweden); DCC-AZ = aliquots AZ-preserved and analyzed by the DCC; DCC-BR = aliquots BR-preserved and analyzed by the DCC; DCC(PBS)-UP = aliquots UP, diluted 1:1 in PBS solution, and analyzed by the DCC; DCC(PBS + EB)-UP = aliquots UP, diluted 1:1 in PBS + ethidium bromide (EB) staining solution, and analyzed by the DCC; DCC(PBS + PI)-UP = aliquots UP, diluted 1:1 in PBS + propidium iodide (PI) staining solution, and analyzed by the DCC; DCC(PBS)$\mathrm{AZ}=$ aliquots $\mathrm{AZ}$-preserved, diluted 1:1 in PBS solution, and analyzed by the DCC; DCC(PBS + EB)-AZ = aliquots AZ-preserved, diluted 1:1 in PBS + EB staining solution, and analyzed by the DCC; DCC(PBS + $\mathrm{PI})-\mathrm{AZ}$ = aliquots AZ-preserved, diluted 1:1 in PBS + PI staining solution, and analyzed by the DCC; DCC(PBS)-BR = aliquots BR-preserved, diluted 1:1 in PBS solution, and analyzed by the DCC; DCC(PBS + EB)-BR = aliquots BR-preserved, diluted 1:1 in PBS + EB staining solution, and analyzed by the DCC; $\mathrm{DCC}(\mathrm{PBS}+\mathrm{PI})-\mathrm{BR}=$ aliquots BR-preserved, diluted 1:1 in PBS + PI staining solution, and analyzed by the DCC.

previously in ovine milk (Gonzalo et al., 1993, 2004), and were very large in undiluted ovine milk analyzed by the DCC (12.6 to 19.6\%). The diluted aliquots showed $\mathrm{s}_{\mathrm{r}} \%$ values that ranged between 6.07 and $8.75 \%$ (mean $=$ $7.24 \%$ ), which were closer to values obtained for the DMSCC in this and previous studies (Gonzalo et al., 2003, 2004). Differences among methods for repeatability are likely explained on the basis of differences in the counting principle for each method. Thus, similar $\mathrm{s}_{\mathrm{r}}$ values were found for the DCC (33 to $48 \times 10^{3}$ cells $/ \mathrm{mL}$ ) and DMSCC $\left(36 \times 10^{3}\right.$ cells $\left./ \mathrm{mL}\right)$ methods, which are based in the same principle (i.e., staining and counting of cells contained in a volume of milk spread in a specific area), whereas the Fossomatic 5000 used in this study, which is based on flow cytometry, showed the smallest $\mathrm{S}_{\mathrm{r}}$ values (13 to $16 \times 10^{3}$ cells $/ \mathrm{mL}$ ).

Regression studies between the DMSCC (reference method) and all analytical conditions and methods assayed are shown in Table 2 . The $\mathrm{R}^{2}$ values were very large in all cases $\left(R^{2} \geq 0.99\right)$, except for the undiluted samples analyzed by the DCC (0.94 to 0.98$)$. The greatest coefficients of regression (b) were for the FSCC method
(0.96 to 0.97 ), and for aliquots diluted in staining solution with EB (0.95 to 0.98 ) analyzed by the DCC, coinciding with the smallest intercept values ( $\mathrm{a}=0.12$ to 0.27 ). The smallest coefficients of regression $(0.85$ to 0.91$)$ and the largest intercept values ( 0.35 to 0.65$)$ were for undiluted aliquots analyzed by the DCC. The remaining analytical conditions showed intermediate $\mathrm{b}(0.91$ to 0.94$)$ and a (0.31 to 0.52 ) values. Large intercepts indicated compromised accuracy and repeatability of samples with low SCC (Figure 1). In this sense, when these regression studies were repeated forcing $a=0$, the $b$ values increased in all cases (Table 2). In particular, the coefficients of regression were $>0.99$ for diluted aliquots analyzed by the DCC and for undiluted milk analyzed by the FSCC. The precision of the SCC methods was dependent on the working factor and the number of cells in a sample (Schalm et al., 1971). Smaller SCC produced less accuracy in the estimate when using a constant working factor. In spite of this, poor accuracy in milk having lower SCC is not important from a biological and operational point of view, because having fewer somatic cells indicates a good health status of the udder. Because the 


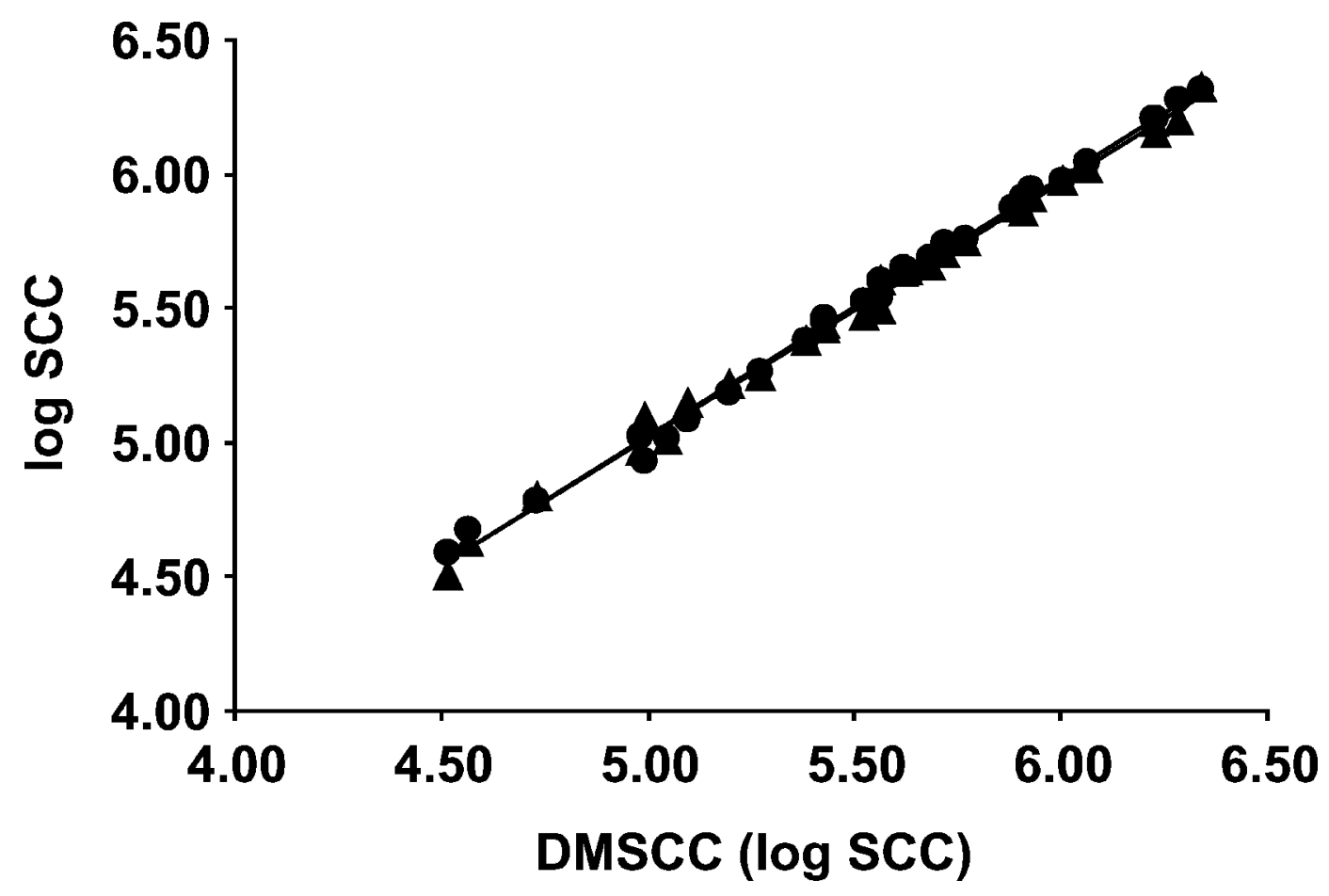

Figure 1. Regression lines between the reference microscopic method (direct microscopy; DMSCC) and the Fossomatic (Foss Electric, Hillerød, Denmark; $\bullet$ ) method (unpreserved samples) and DeLaval cell counter (DeLaval International AB, Tumba, Sweden; $\mathbf{\Delta}$ ) method (unpreserved samples diluted 1:1 in PBS + ethidium bromide staining solution).

SCC threshold that discriminates infected and uninfected udders is about 200 to $400 \times 10^{3}$ cells/mL in dairy ewes (Marco, 1994; González-Rodríguez et al., 1995), the accuracy of the DCC method is perfectly guaranteed for those values. On the other hand, a small loss of accuracy also was observed in the case of very high SCC (Figure 1), similar to the FSCC equipment based on disk cytometry (Gonzalo et al., 2004). The loss of accuracy occurs because of a cellular superimposition in the DCC count window in milk having greater SCC, although a high ratio of cells/pixels when the images were digitally processed also should be considered. In this sense, the Fossomatic 5000 used in this study, which is based on flow cytometry, gave slightly more accurate estimates in samples having elevated SCC (Figure 1).

When the FSCC was considered as the reference method (Table 3), regression performance was improved in comparison with the DMSCC, because $b$ values increased and a values decreased in all cases. Similar to the results shown in Table 2, the better analytical conditions were for samples diluted in staining solution with EB ( $b=0.98$ to 1.01 and $a=-0.08$ to 0.09$)$ and PI $(b=0.94$ to 0.98 and $\mathrm{a}=0.12$ to 0.34 ). Samples diluted in PBS showed slightly lower accuracies $(b=0.94$ to 0.95 and $\mathrm{a}=0.23$ to 0.30 ). Regression analyses were carried out considering, as reference methods, the 3 FSCC analytical conditions studied (unpreserved, BR- preserved, and AZpreserved samples), although very similar results were always obtained in the 3 regression studies, because coefficients of regression among these FSCC conditions were very close to 1.0 (Table 3 ).

As a whole, correlations obtained between the reference methods and the DCC in diluted ovine samples coincided with values reported from comparisons between the DMSCC and FSCC for undiluted ovine (Gonzalo et al., 1993, 2003) and bovine (Heeschen, 1975; Schmidt-Madsen, 1975; Heald et al., 1977) milk samples by other authors using different working factors.

In a previous experiment we investigated the accuracy and repeatability of the DCC in 23 raw bovine milk samples (which ranged between $47 \times 10^{3}$ and $1,940 \times$ $10^{3}$ cells $/ \mathrm{mL}$ and averaged $12.1 \pm 1.7 \%$ of solids content), the single and forced by $a=0$ regression lines for log SCC values, in comparison with the FSCC method, were as follows: $\mathrm{y}=0.96 \mathrm{x}+0.20\left(\mathrm{R}^{2}=0.993\right)$ and $\mathrm{y}=0.99 \mathrm{x}$ $\left(R^{2}=0.991\right)$, respectively. The standard deviation of repeatability $\left(\mathrm{s}_{\mathrm{r}} \%\right)$ for DCC was $5.2 \%$. The poor performance observed in undiluted ovine milk, compared with bovine milk and with diluted ovine milk, seems to indicate some difficulties with the DCC for counting milk having an elevated solids content. Indeed, the mean $( \pm \mathrm{SD})$ values of the fat, protein, and solids content for 
Table 3. Coefficients of regression (b), intercepts (a), standard errors (SE), and $\mathrm{R}^{2}$ values based on regression analyses between the Fossomatic method in unpreserved samples (as the reference method) and the SCC methods and analytical conditions studied

\begin{tabular}{|c|c|c|c|c|c|}
\hline $\begin{array}{l}\text { SCC methods } \\
\text { and analytical } \\
\text { conditions }^{1}\end{array}$ & b & SE & a & SE & $\mathrm{R}^{2}$ \\
\hline FSCC-AZ & 1.007 & 0.006 & -0.035 & 0.036 & 0.999 \\
\hline FSCC-BR & 1.009 & 0.007 & -0.040 & 0.038 & 0.999 \\
\hline DCC-UP & 0.934 & 0.031 & 0.188 & 0.171 & 0.972 \\
\hline DCC-AZ & 0.880 & 0.038 & 0.486 & 0.214 & 0.951 \\
\hline DCC-BR & 0.896 & 0.045 & 0.371 & 0.253 & 0.935 \\
\hline DCC(PBS)-UP & 0.950 & 0.019 & 0.232 & 0.108 & 0.989 \\
\hline $\mathrm{DCC}(\mathrm{PBS}+\mathrm{EB})-\mathrm{UP}$ & 0.981 & 0.017 & 0.090 & 0.097 & 0.991 \\
\hline DCC(PBS + PI)-UP & 0.976 & 0.012 & 0.116 & 0.067 & 0.996 \\
\hline DCC(PBS)-AZ & 0.936 & 0.018 & 0.301 & 0.099 & 0.990 \\
\hline $\mathrm{DCC}(\mathrm{PBS}+\mathrm{EB})-\mathrm{AZ}$ & 1.009 & 0.024 & -0.076 & 0.134 & 0.985 \\
\hline DCC(PBS + PI)-AZ & 0.938 & 0.016 & 0.336 & 0.090 & 0.992 \\
\hline DCC(PBS)-BR & 0.943 & 0.022 & 0.275 & 0.122 & 0.986 \\
\hline $\mathrm{DCC}(\mathrm{PBS}+\mathrm{EB})-\mathrm{BR}$ & 0.995 & 0.016 & 0.004 & 0.088 & 0.993 \\
\hline DCC(PBS + PI)-BR & 0.944 & 0.015 & 0.303 & 0.085 & 0.993 \\
\hline
\end{tabular}

${ }^{1}$ FSCC-AZ = Aliquots preserved with azidiol (AZ) and analyzed by the Fossomatic (FSCC; Foss Electric, Hillerød, Denmark); FSCC-BR = aliquots preserved with bronopol (BR) and analyzed by the FSCC; DCC$\mathrm{UP}=$ aliquots unpreserved (UP) and analyzed by the DeLaval cell counter (DCC; DeLaval International AB, Tumba, Sweden); DCC-AZ = aliquots AZ-preserved and analyzed by the DCC; DCC-BR = aliquots BRpreserved and analyzed by the DCC; DCC(PBS)-UP = aliquots UP, diluted 1:1 in PBS solution, and analyzed by the DCC; DCC(PBS + EB)-UP = aliquots UP, diluted 1:1 in PBS + ethidium bromide (EB) staining solution, and analyzed by the DCC; DCC(PBS + PI)-UP = aliquots UP, diluted 1:1 in PBS + propidium iodide (PI) staining solution, and analyzed by the DCC; DCC(PBS)-AZ = aliquots AZ-preserved, diluted 1:1 in PBS solution, and analyzed by the DCC; DCC(PBS + EB)-AZ = aliquots AZ-preserved, diluted 1:1 in PBS + EB staining solution, and analyzed by the DCC; DCC(PBS + PI)-AZ = aliquots AZ-preserved, diluted 1:1 in PBS + PI staining solution, and analyzed by the DCC; DCC(PBS)-BR = aliquots BR-preserved, diluted 1:1 in PBS solution, and analyzed by the DCC; DCC(PBS + EB)-BR = aliquots BR-preserved, diluted 1:1 in PBS + EB staining solution, and analyzed by the DCC; DCC(PBS + PI)-BR = aliquots BR-preserved, diluted 1:1 in PBS + PI staining solution, and analyzed by the DCC.

29 ovine milk samples in this study were $7.0 \pm 1.2 \%, 5.8$ $\pm 0.7 \%$, and $18.3 \pm 1.7 \%$, respectively. A high fat and protein content might interfere with both cell stimulation and cell pulse emission and produce small SCC values. Consequently, milk dilution with a staining solution based in PBS containing fluorescent stains, such as $\mathrm{EB}$ or PI, could optimize cell nuclei staining and increase the accuracy and repeatability of the DCC method.

These results for overall accuracy were confirmed in the study on factors influencing SCC. The ewe and SCC method contributed $(P<0.001)$ notably to SCC variation; however, preservation type and method $\times$ preservation interaction did not influence the SCC variation. In previous studies in ovine milk, preservation type had a significant effect on results with the FSCC. The smallest SCC always corresponded to milk preserved with sodium azide (Gonzalo et al., 2003, 2004; Sánchez et al., 2005). This result was not obtained for the FSCC in the present study, probably because of the different formulation of sodium azide used now. In this sense, azidiol is a more stable sodium azide solution that also includes cloramphenicol, ethanol, trisodium citrate 5.5-hydrate, and bromophenol blue.

The effect of the SCC methods is shown in Table 4. In comparison with the DMSCC and FSCC reference methods $(\log \mathrm{SCC}=5.54$, and geometric mean $=344$ to $350 \times 10^{3} / \mathrm{mL}$ ), the optimal analytical conditions for determination with the DCC corresponded to milk samples preserved or unpreserved, diluted (1:1) in PI or EB staining solution (5.52 to 5.53 , and 330 to $340 \times 10^{3} / \mathrm{mL}$ ). Under the previously mentioned conditions, the DCC could be used on farms, in milk plants, in transfer and receiving stations, and in ovine milk laboratories. The dilution of milk in PBS without DNA-stain addition (5.49, and $\left.311 \times 10^{3} / \mathrm{mL}\right)$ was related to accuracy losses of about $10 \%$, and this methodology should be limited to only on-farm use in which a certain loss of accuracy can be assumed. Undiluted samples gave the smallest SCC values (5.35 and $224 \times 10^{3} / \mathrm{mL}$ ) and should not be used for analysis. In addition, the DCC device requires a very small volume of milk $(60 \mu \mathrm{L})$ for analysis, thus increasing the versatility of this method (i.e., foremilk samples, samples from bacteriological protocols, experimental studies, etc.) in comparison with the current counters, which require about 30 to $40 \mathrm{~mL}$ of milk for analysis.

\section{CONCLUSIONS}

The DCC is a portable device developed for on-farm use, primarily in raw bovine milk. The results of our 
Table 4. Least squares means of log SCC, and geometric means of SCC of 5 methods studied in ovine milk

\begin{tabular}{|c|c|c|c|c|c|}
\hline Variable & FSCC $^{1}$ & $\mathrm{DCC}(\mathrm{PBS}+\mathrm{PI})^{2}$ & $\mathrm{DCC}(\mathrm{PBS}+\mathrm{EB})^{3}$ & $\mathrm{DCC}(\mathrm{PBS})^{4}$ & $\mathrm{DCC}^{5}$ \\
\hline $\begin{array}{l}\log \mathrm{SCC}^{6,7} \\
\operatorname{SCC}\left(\times 10^{3} / \mathrm{mL}\right)^{6}\end{array}$ & $\begin{array}{l}5.54^{\mathrm{a}} \\
350\end{array}$ & $\begin{array}{l}5.53^{\mathrm{ab}} \\
340\end{array}$ & $\begin{array}{l}5.52^{\mathrm{b}} \\
330\end{array}$ & $\begin{array}{l}5.49^{\mathrm{c}} \\
311\end{array}$ & $2^{5.35^{\mathrm{c}}}$ \\
\hline $\begin{array}{l}{ }^{\mathrm{a}-\mathrm{d}} \text { Means withi } \\
{ }^{1} \mathrm{FSCC}=\text { Fosso } \\
{ }^{2} \mathrm{DCC}(\mathrm{PBS}+\mathrm{P} \\
\text { aliquots diluted } 1 \\
{ }^{3} \mathrm{DCC}(\mathrm{PBS}+\mathrm{E} \\
{ }^{4} \mathrm{DCC}(\mathrm{PBS})=\mathrm{I} \\
{ }^{5} \mathrm{DCC}=\mathrm{DCC} \mathrm{m} \\
{ }^{6} \mathrm{Log} \text { SCC and } \\
\text { tively. }\end{array}$ & $\begin{array}{l}\text { same r } \\
\text { c (Foss } \\
\text { DeLaval } \\
\text { PBS + } \\
\text { DCC me } \\
\text { method } \\
\text { d in und } \\
\text { etric me }\end{array}$ & $\begin{array}{l}\text { ot sharing a comm } \\
\text { ric, Hillerød, Denn } \\
\text { counter (DCC; De } \\
\text { idium iodide stain } \\
\text { in aliquots dilute } \\
\text { iquots diluted } 1: 1 \\
\text { ed aliquots. } \\
\text { alues for direct mi }\end{array}$ & $\begin{array}{l}\text { uperscript letter d } \\
\text { method in undilu } \\
\text { al International Al } \\
\text { olution. } \\
\text { in PBS + ethidiu } \\
\text { BS. } \\
\text { opic method were }\end{array}$ & $\begin{array}{l}(P<0.05) \\
\text { aliquots. } \\
\text { imba, Swede } \\
\text { omide staini } \\
\text { and } 344 \times 10\end{array}$ & $\begin{array}{l}\text { ethod in } \\
\text { lution. } \\
\text {, respec- }\end{array}$ \\
\hline
\end{tabular}

study indicated that use of the DCC in ovine milk also was feasible after dilution because of the high solids content in milk in this species. Although dilution in PBS could be sufficient to guarantee acceptable precision for practical, on-farm purposes, the accuracy was significantly improved when PBS was enriched with DNAspecific stains, such as EB or PI. The coefficients of regression obtained from comparisons between the SCC reference methods and the DCC were always $>0.99$ in forced $\mathrm{a}=0$ regression. Coefficients of correlation $>0.99$ also were obtained in diluted samples. Standard deviations of repeatability were greater than with the FSCC, but similar to the DMSCC. Consequently, the DCC method shows suitable overall accuracy in ovine milk compared with the reference method under the analytical conditions previously mentioned. In addition, the small volume of milk required for analysis and the portability of the DCC device make it a viable alternative compared with other cumbersome and very expensive SCC counters.

\section{ACKNOWLEDGMENTS}

The authors wish to thank to DeLaval International AB (Tumba, Sweden), and to CENSYRA (National Centre for Animal Breeding and Reproduction, Villaquilambre, León, Spain) for their collaboration.

\section{REFERENCES}

DeLaval. 2005. Available: http://www.delaval-us.com/Products/MilkingEquipment/Milk_Quality/DCC/ default.htm Accessed Jun. 23, 2006.

El-Saied, U. M., J. A. Carriedo, and F. San Primitivo. 1998. Heritability of test day somatic cell counts and its relationship with milk yield and protein percentage in dairy ewes. J. Dairy Sci. 81:2956-2961.

González-Rodríguez, M. C., C. Gonzalo, F. San Primitivo, and P. Cármenes. 1995. Relationship between somatic cell count and intra- mammary infection of the half-udder in dairy ewes. J. Dairy Sci. 78:2753-2759.

Gonzalo, C., A. Ariznabarreta, J. A. Carriedo, and F. San Primitivo. 2002. Mammary pathogens and their relationship to somatic cell count and milk yield losses in dairy ewes. J. Dairy Sci. 85:14601467.

Gonzalo, C., J. A. Baro, J. A. Carriedo, and F. San Primitivo. 1993. Use of the Fossomatic method to determine somatic cell counts in sheep milk. J. Dairy Sci. 76:115-119.

Gonzalo, C., J. C. Boixo, J. A. Carriedo, and F. San Primitivo. 2004. Evaluation of rapid somatic cell counters under different analytical conditions in ovine milk. J. Dairy Sci. 87:3623-3628.

Gonzalo, C., J. A. Carriedo, J. A. Baro, and F. San Primitivo. 1994. Factors influencing variation of test day milk yield, somatic cell count, fat and protein in dairy sheep. J. Dairy Sci. 77:1537-1542.

Gonzalo, C., J. R. Martínez, J. A. Carriedo, and F. San Primitivo. 2003. Fossomatic cell-counting on ewe milk: Comparison with direct microscopy and study of variation factors. J. Dairy Sci. 86:138-145.

Heald, C. W., G. M. Jones, S. C. Nickerson, W. N. Patterson, and W. E. Vinson. 1977. Preliminary evaluation of the Fossomatic somatic cell counter for analysis of individual cow samples in a central testing laboratory. J. Food Prot. 40:523-526.

Heeschen, W. 1975. Determination of somatic cells in milk (technical aspects of counting). Bull. Int. Dairy Fed. 85:79-92.

IDF (International Dairy Federation). 1999. Definition and evaluation of the overall accuracy of indirect methods of milk analysis application to calibration procedure and quality control in the dairy laboratory. FIL-IDF Standard no. 128A. IDF, Brussels, Belgium.

IDF (International Dairy Federation). 1995. Enumeration of somatic cells. FIL-IDF Standard no. 148A. IDF, Brussels, Belgium.

IDF (International Dairy Federation). 2006. Milk-enumeration of somatic cells. Part 2: Guidance on the operation of fluoro-opto-electronic counters. FIL-IDF Standard no. 148-2 (E). IDF, Brussels, Belgium.

Marco, J. C. 1994. Mastitis en la oveja Latxa: Epidemiología, diagnóstico y control. Ph.D. Thesis, Univ. Zaragoza, Zaragoza, Spain.

Martínez, J. R., C. Gonzalo, J. A. Carriedo, and F. San Primitivo. 2003. Effect of freezing on Fossomatic cell counting in ewe milk. J. Dairy Sci. 86:2583-2587.

Sánchez, A., D. Sierra, C. Luengo, J. C. Corrales, C. T. Morales, A. Contreras, and C. Gonzalo. 2005. Influence of storage and preservation on Fossomatic cell count and composition of goat milk. J. Dairy Sci. 88:3095-3100.

Schalm, O. W., E. J. Carroll, and N. C. Jain. 1971. Bovine Mastitis. Lea \& Febiger, Philadelphia, PA.

Schmidt-Madsen, P. 1975. Fluoro-opto-electronic cell-counting on milk. J. Dairy Res. 42:227-239. 